\title{
El tabaquismo y la afectación de la libertad individual.
}

Carta al Editor

Jesús Quintanilla-Osorio.

Coordinación de Regulación Sanitaria. Jurisdicción Sanitaria 1.

Servicios Estatales de Salud de Quintana Roo.

¿Hasta dónde llega tu libertad?

Las campañas actuales para combatir el tabaquismo como un mal social, no han logrado disminuir significativamente, la propagación del consumo de los cigarrillos, aunque las mismas leyendas que ostentan las cajetillas advierten sobre los nocivos efectos para la salud que conlleva tal práctica. Se insiste en forma sistemática sobre los daños a la salud del fumador, y se utilizan muchos ejemplos para disuadir al fumador activo sobre los perjuicios de la nicotina y el alquitrán. Sin embargo, poco se dice sobre los efectos del humo de los cigarros en las personas que rodean al consumidor de tabaco, ni mucho menos sobre la violación a la libertad individual de quien no fuma, y los daños colaterales que incluyen diversas cardiopatías y males como el enfisema o el cáncer pulmonar, con sus funestas consecuencias. Si mi salud es dañada por un fumador activo, se rasga la seguridad de mi propio espacio vital, mi mundo de libertad como ser humano, el valor inherente de mi propia vida.
Vandel expresa muy bien el valor de la vida al señalar que "un hombre no es uno de los representantes intercambiables de una especie, si no una persona diferente a cualquier otra, y por consiguiente, irremplazable. Suprimir un solo hombre es, más o menos, empobrecer la humanidad de una manera segura” (1)

En la actualidad, comienza a vislumbrarse una esperanza para los no fumadores, con la puesta en marcha de un marco regulatorio que establece un espacio para los fumadores en áreas al aire libre en las dependencias del gobierno federal mexicano, y la prohibición de fumar en el interior de tales edificios para salvaguardar la salud del personal que no consume tabaco.

El avanzar hacia una mayor conciencia sobre la libertad individual de quien no práctica tal hábito, depende en mucho de valorar la vida humana en su conjunto, y los esfuerzos gubernamentales serán del todo insuficientes, si en los hogares no se enseñan los peligros de tales prácticas, porque como señala un proverbio, “instruye al niño en su

Solicitud de sobretiros: Jesús Quintanilla-Osorio. Tlaxcalaltongo No. 250 entre Carranza y San Salvador, Col. Venustiano Carranza, C.P. 77000, Chetumal, Quintana Roo, México. Correo electrónico: jesusin06_@hotmail.com 


\section{J Quintanilla-Osorio}

carrera y aun cuando fuere viejo, no se apartará de ella”. Instruir a los pequeños, significa romper un molde donde se equipara el tabaquismo con un símbolo de status, virilidad o una personalidad segura. Dentro de la misma familia, se gesta una vida libre de vicios o se induce a ellos.

La libertad individual, merece el respeto de la sociedad. El tabaquismo, sin un control social que marque los límites para evitar la exposición de los niños, esposas, hermanos y amistades a recibir daños como fumadores pasivos con consecuencias a largo plazo, es un atentado a esta libertad inherente de cada ser humano, y merece un esfuerzo de la sociedad en su conjunto para heredar a nuestras nuevas generaciones, espacios libres de consumo de tabaco.

Palabras clave: Tabaquismo, libertad, fumador pasivo.

\section{REFERENCIA.}

1.- Rostand, J. “Ensayos sobre lo humano”. 1ªd, México: Alianza editorial; 1994. 